\title{
INFLUENCE OF INLET DISTRIBUTOR AND COLUMN DIAMETER ON HYDRODYNAMIC CHARACTERISTICS IN RDC LIQUID EXTRACTION COLUMN
}

\author{
Ayham M. Ismail Al-Rahawi ${ }^{1}$, Salam Kadhim Al Dawery ${ }^{2}$ \\ ${ }^{1}$ Department of Engineering, German University of Technology (GUtech), P.O. Box: 1816, PC 130, Muscat - Sultanate of Oman. \\ ${ }^{2}$ College of Engineering, Department of Petroleum and Chemical Engineering, Nizwa-Oman
}

\begin{abstract}
The factors affecting the hydrodynamic characteristics like hold-up and mean drop diameter were investigated using; four different distributors, two different columns size RDC extraction columns, testing three system, different solute concentration and wide range of operating conditions. Change in behavior of hold-up was observed in experimental data when the distributor holes diameter changed. Hold-up increases with decreasing dispersed phase holes inlet distributor. This behavior, however, can very well be explained by the small drop sizes generated in the lower part of the RDC. Runs have been conducted to determine the hold-up and mean drop diameter as function of the flow rate and rotation disc speed. Experiments were carried out in the presence and absence of mass transfer. The drop size was measured by analysis of images and hold-up by the shut-off method.
\end{abstract}

Keywords; RDC, Liquid Extraction, Holdup, Drop Size, Column Diameter, Distributor

\section{INTRODUCTION}

Dispersed phase hold-up is an essential parameter in the design of extraction columns [1 \& 2]. The hydrodynamics parameters of RDC extraction column, are important parameters in determining the available mass transfer area and the fraction of the active volume, occupied by droplets of the dispersed phase [3].

The efficiency of extraction column is greatly affected by dispersed phase hold-up and the drop size distribution which are essential in determining the interfacial surface area, the mean residence time of the dispersed phase droplets and finally the capacity of the column [4, 5 \& 6].

In liquid extraction column, the nature of the flow and distribution of droplets into continuous phase will significantly affect the mass transfer process. Mixing in extraction column increases the residence time of droplets due to the radial non-uniformity flow structure of droplets [7].

Jaradat et al. [8] used the population balance framework program to study the hydrodynamic parameters and the direction of mass transfer from continuous to dispersed phase and vice versa. They extended program to simulate pilot plant RDC column behavior, where the steady state mean flow properties and the solute concentration profiles compared with the experimental data. Three chemical systems were used; Sulpholane-benzene- n.heptane, Wateracetone-toluene and Water-acetone-n. butyl acetate. The effect of the direction of mass transfer as well as the chemical system, physical properties found to have profound effect on the hold up and steady state performance of the RDC column.

Xuefeng et al. [9] employed three different column diameters to study the scale up and flow regimes effect on holdup. They found that when column diameter less than 15 $\mathrm{cm}$, the holdup decreases with increasing column diameter column diameter for transitional and heterogeneous flow regime, meanwhile the column diameter effects are negligible in the homogeneous flow regime. For column with diameter greater than $15 \mathrm{~cm}$. it appeared that holdup is only affected by column diameter in the transitional flow regime.

Kirou et al. [10] used non-invasive ultrasonic method and toluene-water system to study the effects of the disc speed, continuous and dispersed flow rates on hold up profiles. They reported that the noninvasive ultrasonic method showed a strong non uniformity results. Depending on the operating conditions, hold up profiles can change from a concave shape to a sigmoidal form with maximum in the bottom of the column. They found that the hold-up profile are strongly affected by superficial dispersed phase (represented by the Sauter mean diameter drop size) and disc speed. Significant, but weaker, are the effects of the continuous and dispersed phase flow rates.

Chartres and Korchinsky [11] and Cruz Pinto et al. [12] measured dispersed phase hold up successfully in Rotating Disc Contactors.

Riberio et al. [13] used the ultrasonic technique for the evaluation of the dispersed phase holdup in liquid-liquid extraction columns by measuring the sound propagation travel time in dispersion system. The technique uses the differences between the sound velocities in the dispersed and continuous phases to evaluate the dispersed volume fraction holdup. The experiments showed the dependence of the ultrasound velocity on the holdup and its independents on the size of the droplets forming the dispersion.

Erica et al. [14] studied the hydrodynamic of the $76.2 \mathrm{~mm}$ diameter RDC using water - $\mathrm{n}$ heptane system at low operating conditions and measured the total dispersed phase holdup at different flow rates of $70-640 \mathrm{~mL} / \mathrm{min}$ dispersed flow rate and $0-700 \mathrm{rpm}$ rotor speed. 
Al-Rahawi, A. M. [15] proved that dispersed phase distributor is more effective in controlling drop size and reducing drop breakage than adjusting agitation and control flow in liquid RDC extraction column.

Onink et al. [16] used a rotating disc contactor to study the mean diameters and hold-up for different total fluxes and stirrer speeds. Unexpected behavior for the hold-up was observed in experiments when the RTIL was applied as solvent. At lower fluxes, the hold-up first decreased with increasing rotor speed, at a certain rotor speed, no influence of the rotor speed could be distinguished and, finally, with increasing rotor speed the hold-up increased as expected. With increasing fluxes this behavior diminished. The holdup was measured by taking $250 \mathrm{ml}$ samples of the column content through sample ports. Since the droplets are not finely dispersed everywhere in the compartment, but move or even fall down mainly through the middle of the compartment and accumulate above stirrer and stators, small errors could be introduced in the measurements.

[17] Sá R.m. et al. studied the influence of column height on the dispersed phase hold up. They measured dispersed phase holdup in a liquid-liquid extraction column using butyl alcohol-water system. The column performance has been studied using two columns of the same diameter $(0.092 \mathrm{~m})$ but different lengths $(0.70 \mathrm{~m}$, three stages and $0.90 \mathrm{~m}$, four stages). The column was operated counter-currently with several continuous and dispersed flows rates. The dispersed phase holdup was measured by the drainage method. Based on holdup data, the results were analyzed, an empirical correlation was proposed for estimating the dispersed phase holdup.

\section{EXPERIMENTAL}

The main objective of this paper is to investigate the influence of the dispersed phase inlet distributor and other variables like disc speed, solute transfer, column diameter and phase flow rate on the dispersed phase hold up and drop diameter. Finally to check independently the effect of the column diameter on the dispersed phase hold up.

Previously, drop sizes were controlled by adjusting the operating variables such as phase's flow and disc speed. In this work the effect of inlet distributor on hold up were investigate. Different dispersed phase distributors were used to control drop sizes. Al Rahawi [15] reported, that dispersed phase distributor proved to be more effective in controlling drop size and reducing drop breakage than adjusting agitation and control flow.

Around 110 runs were carried out to measure experimentally the overall dispersed phase holdup in RDC. In this work, the Toluene - Water - Acetone system was mainly used. Some of runs carried out in of the presence of mass transfer and some other in the absence of mass transfer. When mass transfer runs carried out, acetone (solute) transfer from water (continuous phase) to the Toluene (dispersed phase).

Meanwhile in the absence of mass transfer, the toluene dispersed into the continuous water phase. In the two cases, toluene dispersed to water to avoid the coalescence of small drops and large drop size encountered when the aqueous phase is dispersed.

\section{EQUIPMENT}

A schematic flow diagram of the experimental apparatus is shown in Figure - 1;

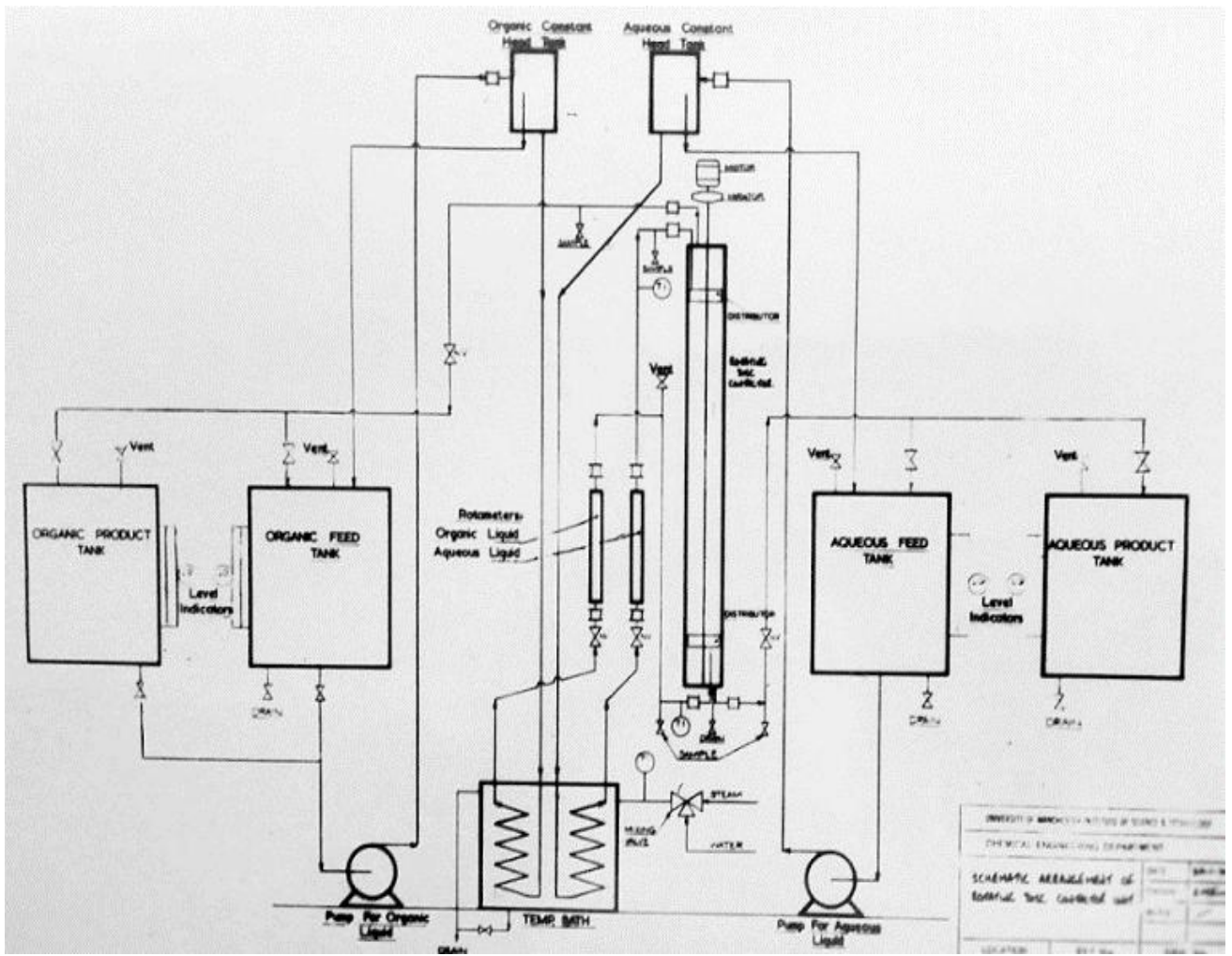

Figure - 1: A schematic flow diagram of the experimental apparatus 
Pilot plant equipment units, consist of 3 inch Rotating disc extraction column was used. A QVF glass column shell of 36 inch height, fitted with two perforated stainless steel distributors, one for the dispersed and other for the continuous phase, placed at the opposite ends of the column.

Four different distributor were designed and used. This will enable the introducing of drops into the column at size which did not suffer from any significant reduction in the range of disc speed used. Thus the variation in the drop diameter with column height was limited.
A precaution was taken to design distributors so that they all have approximately the same total hole area of 0.088 to $0.095 \mathrm{~cm}^{2}$. This gives all runs, the same range of flow rate, but different jet hole velocities. Controlling hole velocity in the jetting region was found to give better control of drop size and finally constant dispersed phase drop velocities. The jet velocities were therefore kept above the minimum jet velocity of about $36 \mathrm{~cm} / \mathrm{s}$, through the holes. Description of the dispersed phase distributors is tabulated in Table -1 and shown in Figure -2;

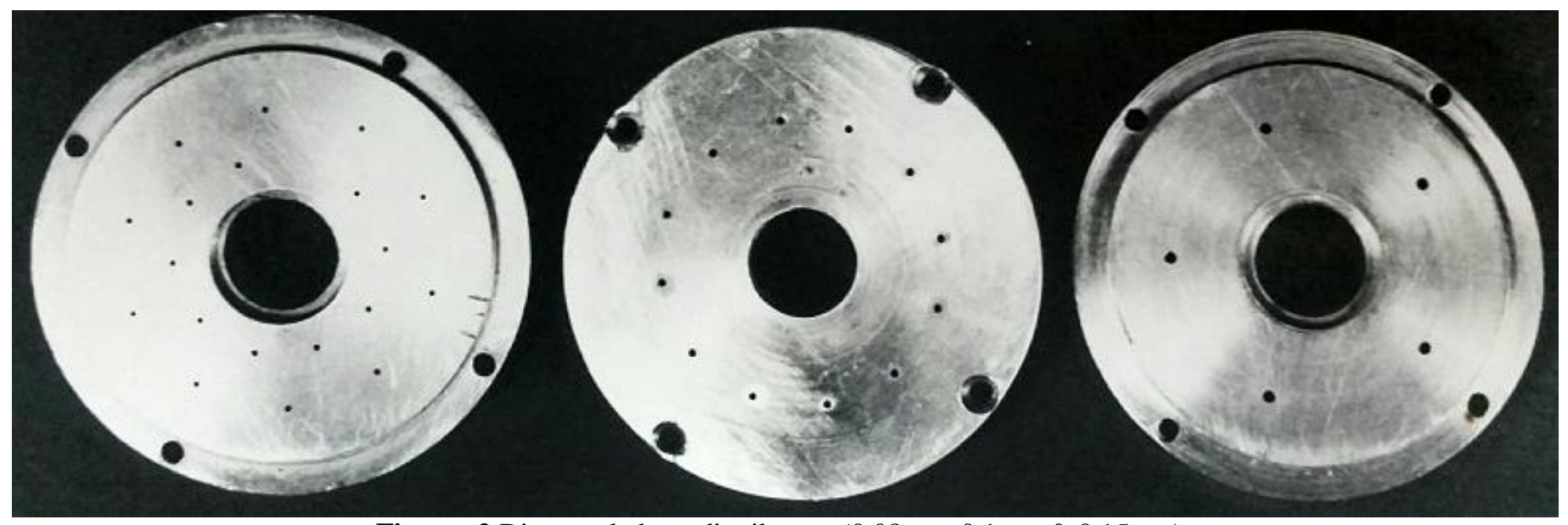

Figure -2 Dispersed phase distributors $(0.08 \mathrm{~cm}, 0.1 \mathrm{~cm} \& 0.15 \mathrm{~cm})$

Table 1: Description of the dispersed phase distributors

\begin{tabular}{|c|c|c|c|c|}
\hline $\begin{array}{c}\text { Distributor Plate } \\
\text { Number }\end{array}$ & $\begin{array}{c}\text { Average dispersed phase hole } \\
\text { diameter } \mathrm{d}_{\mathrm{h}}(\mathrm{cm})\end{array}$ & $\begin{array}{c}\text { Number of } \\
\text { hole }\end{array}$ & Area of hole $\left(\mathrm{cm}^{2}\right)$ & $\begin{array}{c}\text { Total hole area } \\
\left(\mathrm{cm}^{2}\right)\end{array}$ \\
\hline I & $0.080 \pm 0.0015$ & 19 & 0.00503 & 0.0955 \\
\hline II & $0.100 \pm 0.0015$ & 12 & 0.00786 & 0.0943 \\
\hline III & $0.122 \pm 0.0015$ & 8 & 0.00117 & 0.0936 \\
\hline IV & $0.150 \pm 0.0015$ & 5 & 0.0177 & 0.0884 \\
\hline
\end{tabular}

The RDC column zones used in this study consisted almost of agitated zone, but small settling zone existed above the agitated zone, for the settling of drops.

The internals of the column were designed to give more space at the top of the column to adjust the level and position of the interface. This was done by raising the upper continuous phase distributor $6 \mathrm{~cm}$ over the top compartment, to increase the settling zone and make it easier to measure, check and calculate accurately the dispersed phase hold up.

The rotating discs were driven by 0.25 h.p flameproof motor. The speed could be adjusted by a manual speedometer regulator. A tachometer was used to measure the agitator speed.

The column internal manufactured of stainless steel, consisted of 27 compartments, made up of 28 stator rings weld to two thin support rods, each with a diameter of 0.48 $\mathrm{cm}$, and 27 equidistant rotating discs. These were attached to central shaft, which rested on a Teflon bearing at the bottom of the column. Each compartment was $2.54 \mathrm{~cm}$ in height.

In order to provide a unique foundation for comparing the results of this work with previous works, data of AlHusseini [18] was selected for use in this study, who used a larger column of $21.9 \mathrm{~cm}$. diameter, but used similar technique, procedure and operating conditions to examine the effect of column diameter on the mean drop diameter and hold up.

The main dimensions of the two RDC column are given in Table2; 
Table 2: The main dimensions of the two RDC columns

\begin{tabular}{|c|c|c|c|}
\hline Item & Symbol & $\begin{array}{c}\text { Small column } \\
\text { dimensions(cm) }\end{array}$ & $\begin{array}{c}\text { Large column } \\
\text { dimensions(cm) }\end{array}$ \\
\hline Column diameter & $\mathrm{D}_{\mathrm{c}}$ & 7.62 & 21.9 \\
\hline Stator ring diameter & $\mathrm{D}_{\mathrm{s}}$ & 4.5 & 12.934 \\
\hline Disc diameter & $\mathrm{D}$ & 4.0 & 11.496 \\
\hline Compartment Height & $\mathrm{h}_{\mathrm{c}}$ & 2.54 & 1.3 \\
\hline Column working height & $\mathrm{Z}$ & 73 & 150 \\
\hline
\end{tabular}

The flows of both phases were controlled by four needle valves. Two were in the feed lines before two Rota meters, and the other two valves in the outlet lines of the continuous and the dispersed phases. The continuous phase outlet valve was used to control the position of the interface inside the column.

\section{PROCEDURE}

The dispersed phase hold up was measured as follow; the pumps of both phases were switched on. The agitator was switched on and manual speedometer controller adjusted to set the speed to the desire value. The needle valve controlling the dispersed phase flow was opened gradually to obtain the desired flow rate, at the same time the continuous phase outlet valve was opened partially to keep the level of the interface constant over the continuous phase distributor. The dispersed phase was left to flow through the column for five minutes to achieve a uniform flow through the column, and to discharge all the air from the organic line after the column. The continuous phase valve opened gradually to obtain the desired flow rate, at same time valve was adjusted to balance the continuous phase flow into column and to keep the interface position constant at the upper distributor. After steady state achieved, after about 25 minutes, with the interface position and rota-meter reading staying constant at the desired flow rate, the dispersed phase droplets at the bottom and top compartments were photographed. The position of the interface was marked. The height of the interface above the top distributor plate was measured, to be used in correcting the measured holdup using new correlation. All valves around the column were closed simultaneously, so toluene and water were trapped in the column. Dispersed phase droplets were allowed to accumulate at the top of the column. The new interface was marked. The agitator was switched off. The continuous phase was fed slowly to the column, to displace the dispersed phase and to bring the interface level to the origin mark. The displaced dispersed phase was collected into a beaker and its volume was measured. For mass transfer runs, $2.5 \%$ acetone was dissolved in water, and an identical step to those mentioned above was followed.
Photography technique was used to measure the drop diameter, as it proved to be more accurate and reliable than others technique. To account for the change of drop size with column height, 300 droplets were photographed at the bottom and another 300 droplets at top compartment, by means of high speed Camera, in the presence and absence of mass transfer. A computer program was used to predict the Average mean drop diameter from the 600 drops (measured at top and bottom compartments) in each of the 100 runs carried out, using Mugele - Evans function.

Three different system of high, intermediate and low interfacial surface tension, were selected to check the effect of the physical properties on the mean drop diameter.

With Al Husseni, only two of his distributors were selected and used in this study as they have same hole diameter of 0.1 and $0.15 \mathrm{~cm}$. as distributor II and IV used in this study, so they all possess unique range of jet velocities.

\section{RESULTA AND DISCUSSION}

The main objectives in this study is to test the dispersed phase distributor and major independent variables that control dispersed phase hold up and drop diameter in RDC column.

The effects of inlet distributor and operating conditions on dispersed phase hold up were examined experimentally. In addition, effect of average mean drop diameter $\left(\mathrm{d}_{32}\right)$ on hold up was also tested and is found major and can't be neglected. The influence of column geometry, physical properties and solute concentration on dispersed phase hold up was also tested using two different size RDC columns.

\section{EFFECT OF DISPERSED PHASE DISTRIBUTOR}

With all runs presented in the Figure-3, the dispersed phase hold up generated in the RDC column were strongly affected by the distributor devices used. Higher dispersed hold up were obtained with smaller distributor hole diameters. This is due to smaller drop size generated from smaller hole distributors as seen in Figure-4. 

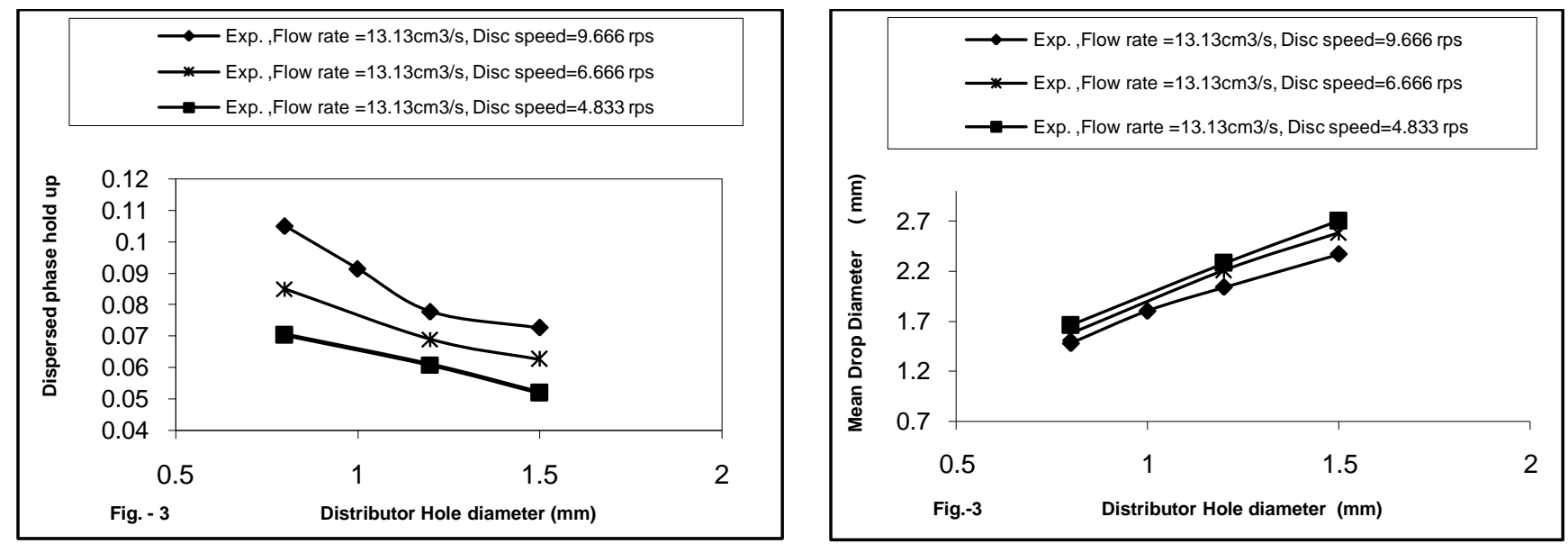

Figure-3\& 4: Dispersed phase holdup \& drop diameter, Influence of distributor hole diameter

The effects of hole distributor on dispersed phase hold up was much more apparent with small hole distributor than with larger one, due to the increased in the drop size.

\section{EFFECT OF FLOW RATE}

The effect of flow rate on hold up was tested using four different distributors, which ignored by previous works.

\subsection{Effect of Total Flow (Dispersed and Continuous}

\section{Phases):}

In order to inspect the effect of increasing the total flow rate on hold up independently by minimizing the drag affect between the two phases, the ratio of the dispersed phase to the continuous phase was kept approximately constant around 1.24, (i.e $\mathrm{Q}_{\mathrm{d}} / \mathrm{Q}_{\mathrm{c}}=1.24$ ) to neutralize the drag force effect between the two phases.

As seen in Figure-5, for all runs with distributor 1, II, III and IV, the dispersed phase holdup increased with increasing the total flow rate. These obvious increases in the dispersed hold-up attributed mainly to the increases in the dispersed phase input inside the column and to the reduction in the drop diameter as seen in figure-6:
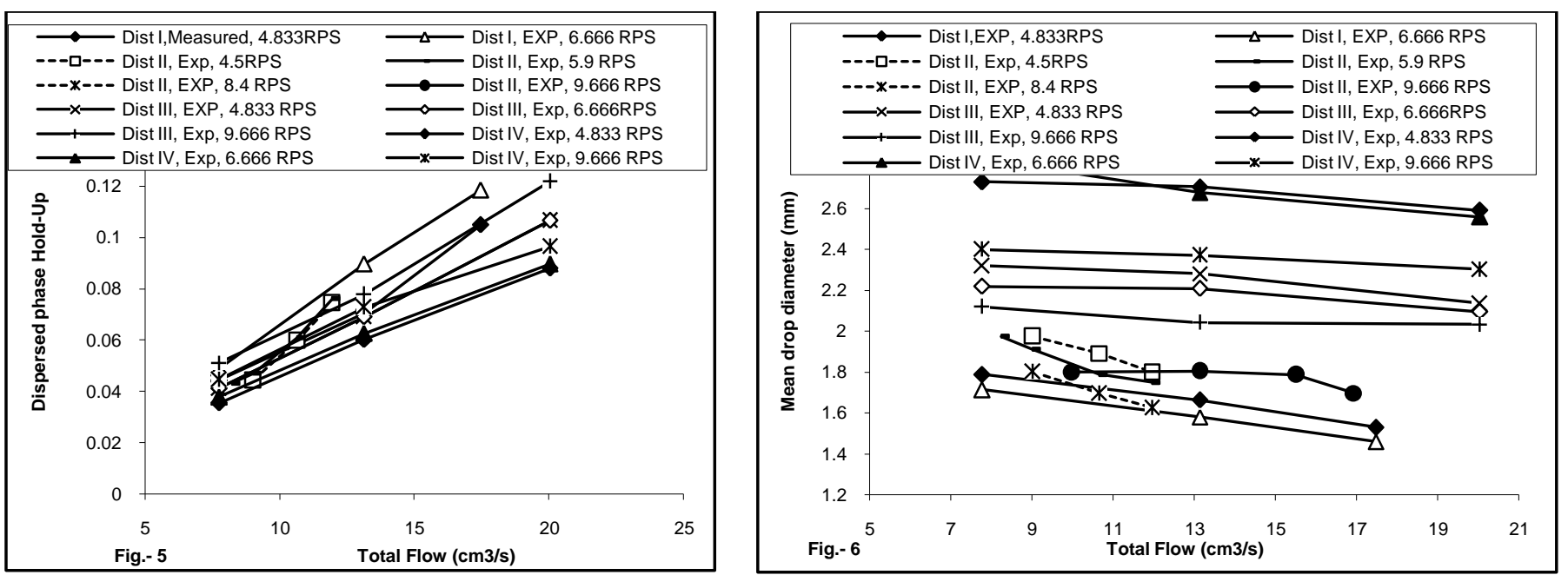

Figure-5 \& 6: Dispersed phase hold up \& drop diameter, Effect of Total flow (For all distributors)

With all four distributors, increasing total flow rate, keeping ratio of dispersed to continuous phase flow rate constant, resulted in close reduction in the average mean drop diameter and approximately a unique increased in the average hold-up. The overall average changes are summarized in Table 3: 
Table-3: Average changes in flow rate, drop size and hold up

\begin{tabular}{|c|c|c|c|}
\hline $\begin{array}{c}\text { Distributor } \\
\text { Number }\end{array}$ & $\begin{array}{c}\text { \% increase in Total flow } \\
\text { rate }\end{array}$ & $\begin{array}{c}\text { \% reduction in Drop } \\
\text { diameter }\end{array}$ & $\begin{array}{c}\text { increase in } \\
\text { Holdup }\end{array}$ \\
\hline Distributor I & 125 & 18.3 & 175 \\
\hline Distributor II & 105 & 17 & 177 \\
\hline Distributor III & 160 & 18.4 & 180 \\
\hline
\end{tabular}

With distributor I; the huge increases in hold-up of $175 \%$ could be resulted from very smaller drops generated from small distributor's holes (see figures 7-1 and 8-1). Maximum flow rate used with Distributors I \& II was around $17.4 \mathrm{~cm}^{3} / \mathrm{s}$. as it was difficult to operate the column at higher flow rate as it close flooding conditions. Also with distributor II, it was hard to work beyond this flow rate due to difficulty in controlling the position of interface and
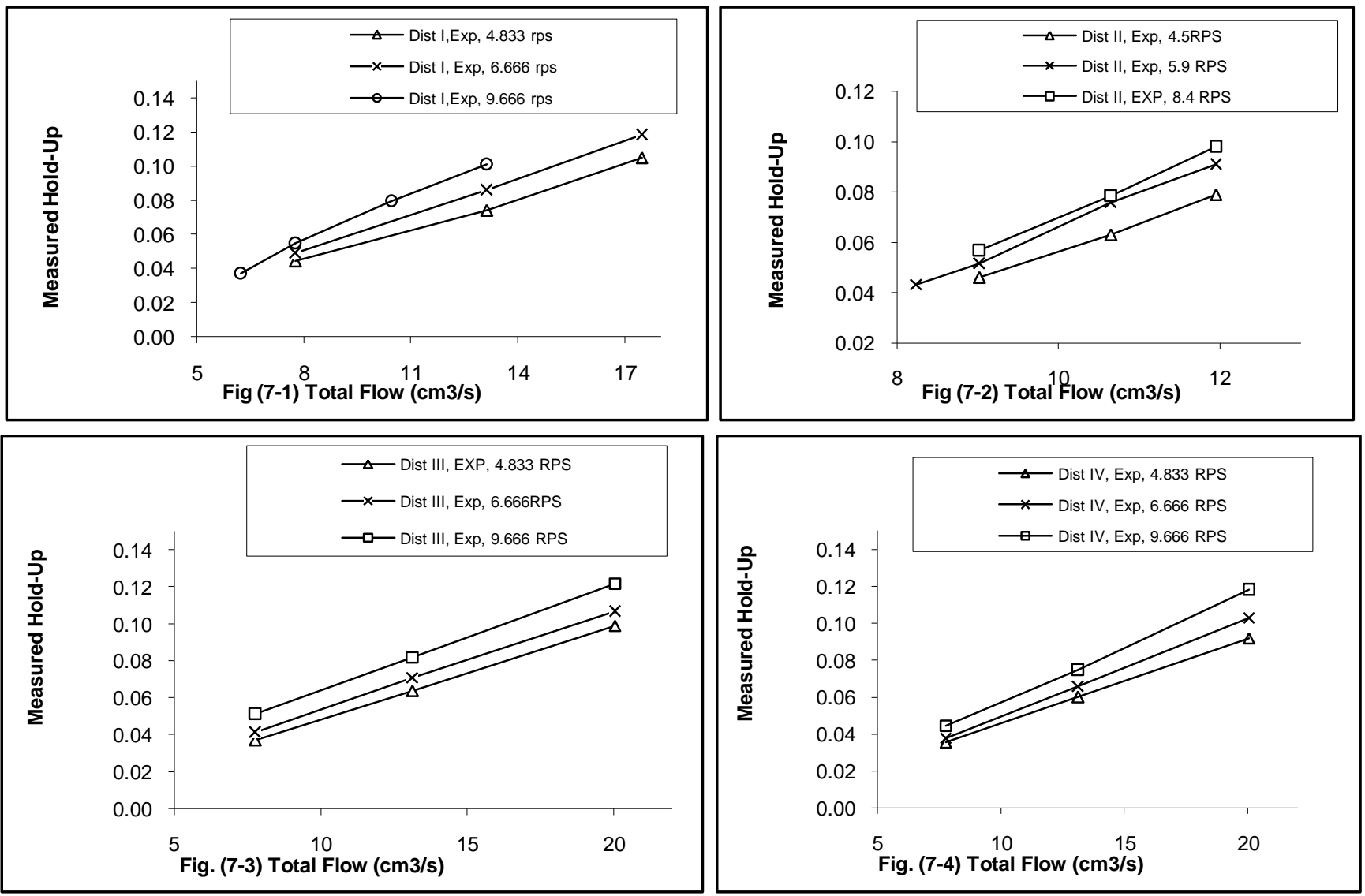

Figure-7: Dispersed phase hold up, Effect of dispersed phase flow (Dist. I, II, III \& IV)
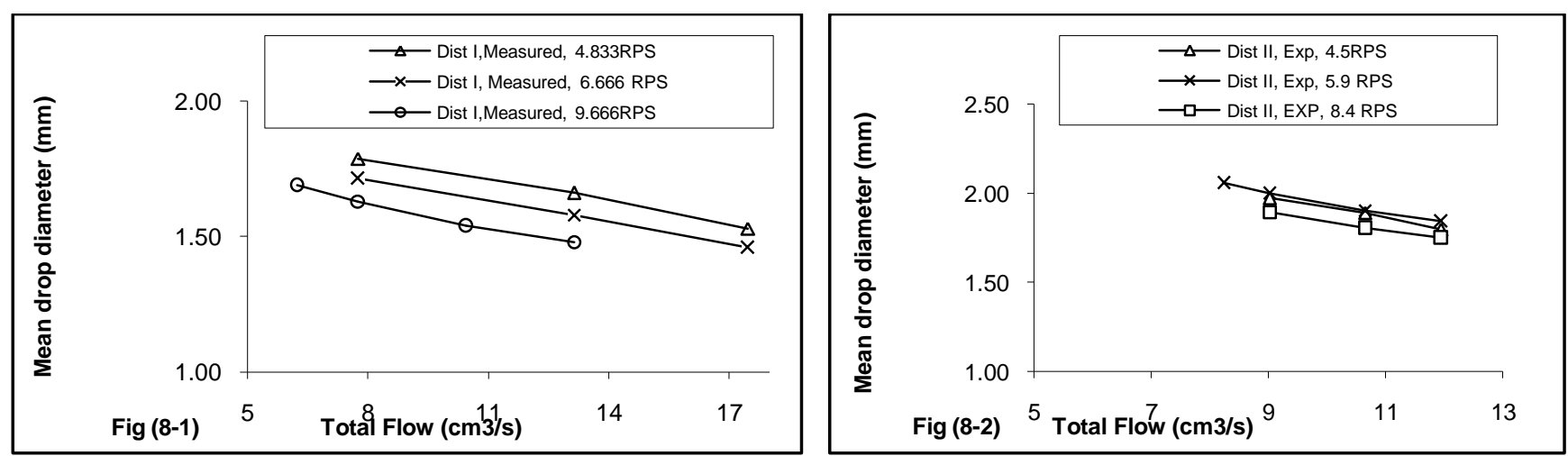

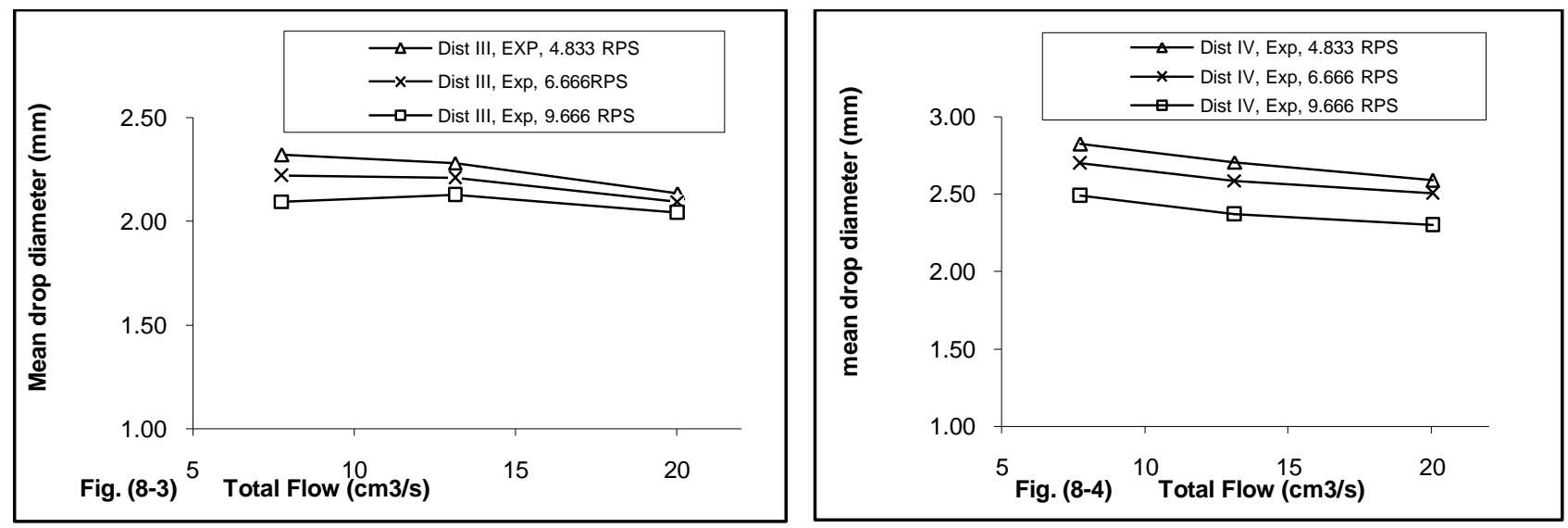

Figure-8: Dispersed phase drop diameter, Effect of dispersed phase flow (Dist. I, II, III \& IV)

\subsection{Effect of Dispersed Flow Rate;}

The effects of increasing the dispersed phase flow rate on dispersed phase hold up and drop diameter were tested and are illustrated, as show in figure $-9 \& 10$;
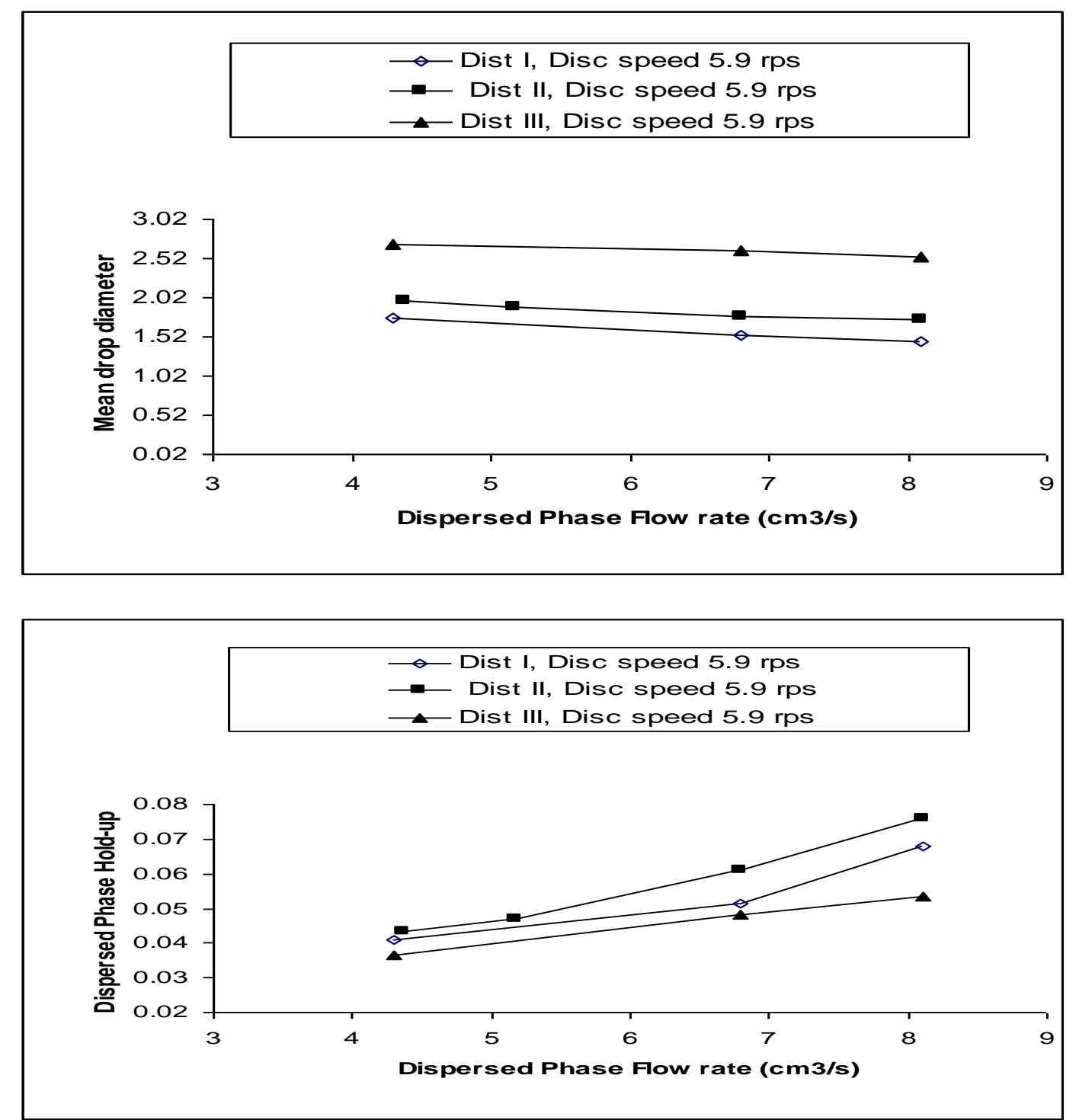

Figure-9 \& 10: Dispersed phase hold up \& drop diameter, effect of dispersed phase flow rate. 
The increase in the hold-up was a result of the increase in the dispersed phase in put inside the column. This is valid since the variation in mean drop diameters with increasing flow were insignificant (see Figure -10), except for runs with small hole distributor I, where only $20 \%$ decrease in $\mathrm{d}_{32}$ was obtained, where total flow increased by $125 \%$ (from 7.759 to $17.46 \mathrm{~cm}^{3} / \mathrm{s}$ ).

\subsection{Effect of Continuous Phase Flow Rate;}

The effects of the continuous phase flow on the dispersed phase hold up is illustrated in figure- $11 \& 12$, for runs with distributors I and III. The dispersed phase hold up, from distributor I, increased slightly as the continuous phase flow increased, this could not be attribute to reduction in the drop size, as there was slight reduction in drop size generated near to the bottom distributor. Accordingly, the slight change in dispersed phase hold up could be due to the drag force developed by the continuous phase on dispersed droplet, resulting in more resistance to the jet rise which might accelerate the drop breakup and lead to the formation of smaller drop with low velocity.

Dispersed phase hold up from distributor III experienced negligible change.

It is obvious that the change in the dispersed phase hold up is greater with the change in the dispersed phase flow rate than with change in the continuous flow. This is due to the fact that the velocity of the continuous phase is much smaller than the terminal velocities of the drops, and changes have little influence, particularly at low flows.
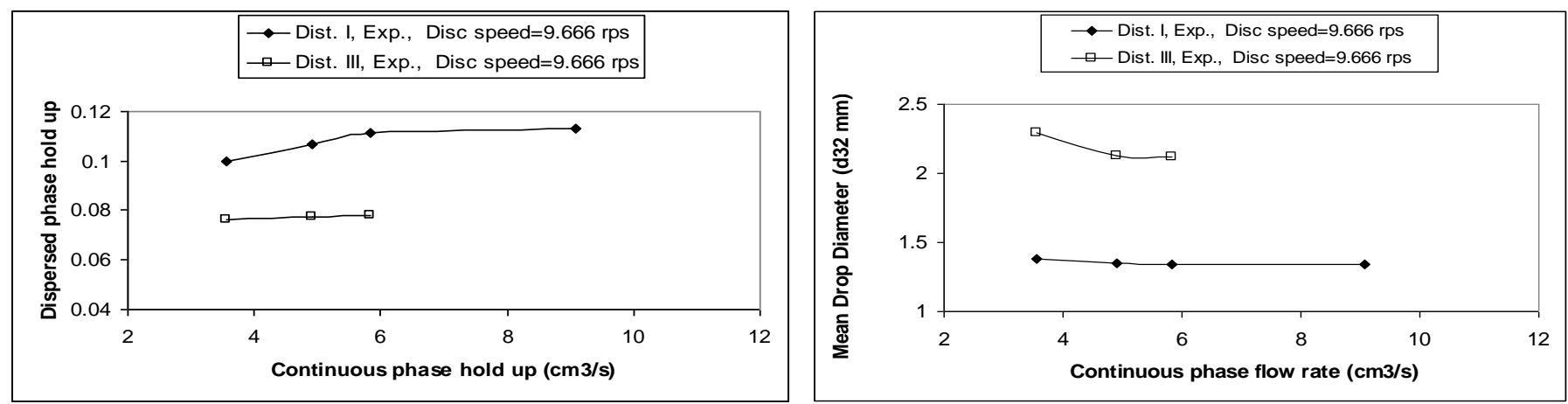

Figure -11 \&12: Hold up \& Mean drop diameter, effect of Continuous phase flow (Distributors I, III)

\subsection{Effect of Phase Ratio:}

The effect of phase flow ratio was studied in this section by changing the ratio of dispersed phase flow to the continuous phase flow rate, but keeping total flow rate constant for each set of run.
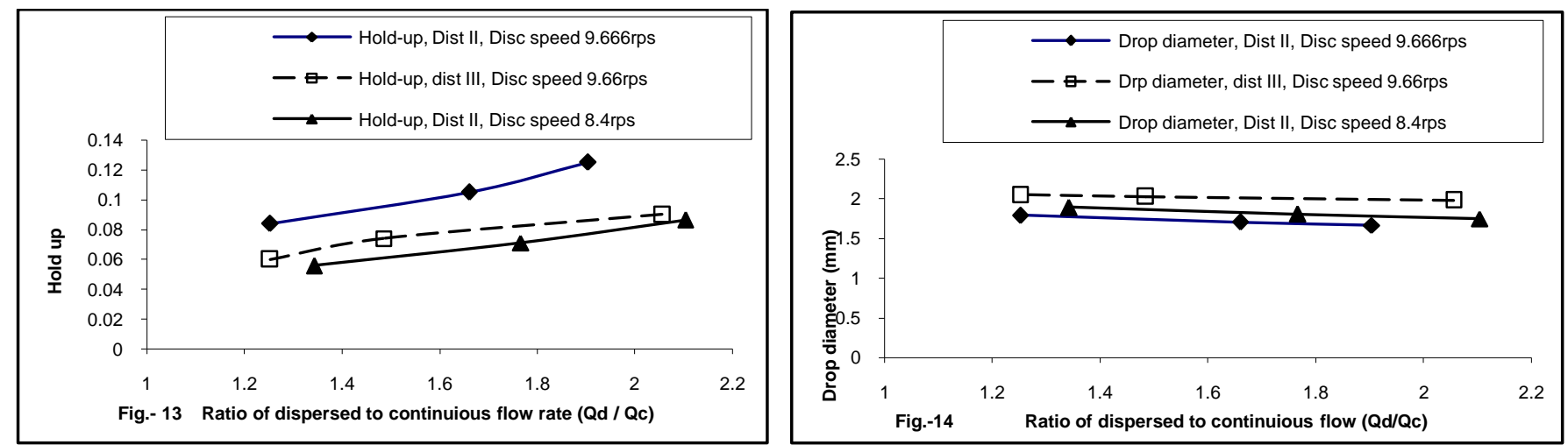

Figure-13 \& 14: Dispersed phase hold up \& Mean drop diameter, effect of phase ratio (Distributors II, III)

As seen in figure -13 ; the change in the phase ratio caused slight increases in the dispersed phase hold-up for set of runs carried at low flow rate of $7.759 \mathrm{~cm} 3 / \mathrm{s}$, which could be attributed to the slight decreases in the mean drop diameter as illustrated in figure- 14. Meanwhile, for two sets of runs carried at higher flow rate of $10.5 \& 12.215 \mathrm{~cm}^{3} / \mathrm{s}$, the increases in the hold-up were obvious. This could be resulted from the decreases in the drop diameter in addition to the increases in the counter forces exhibited by the increase in the continuous phase flow rate against the dispersed phase jet.

\section{EFFECT OF DISC SPEED}

As shown in Figure - 5, with increasing disc speed, dispersed phase hold-up increased for all runs and with all four distributors. This is due to some reduction in the drop diameters (see Figure - 16) and to an increase in the resistance to flow resulting from increases in the level of turbulence: 

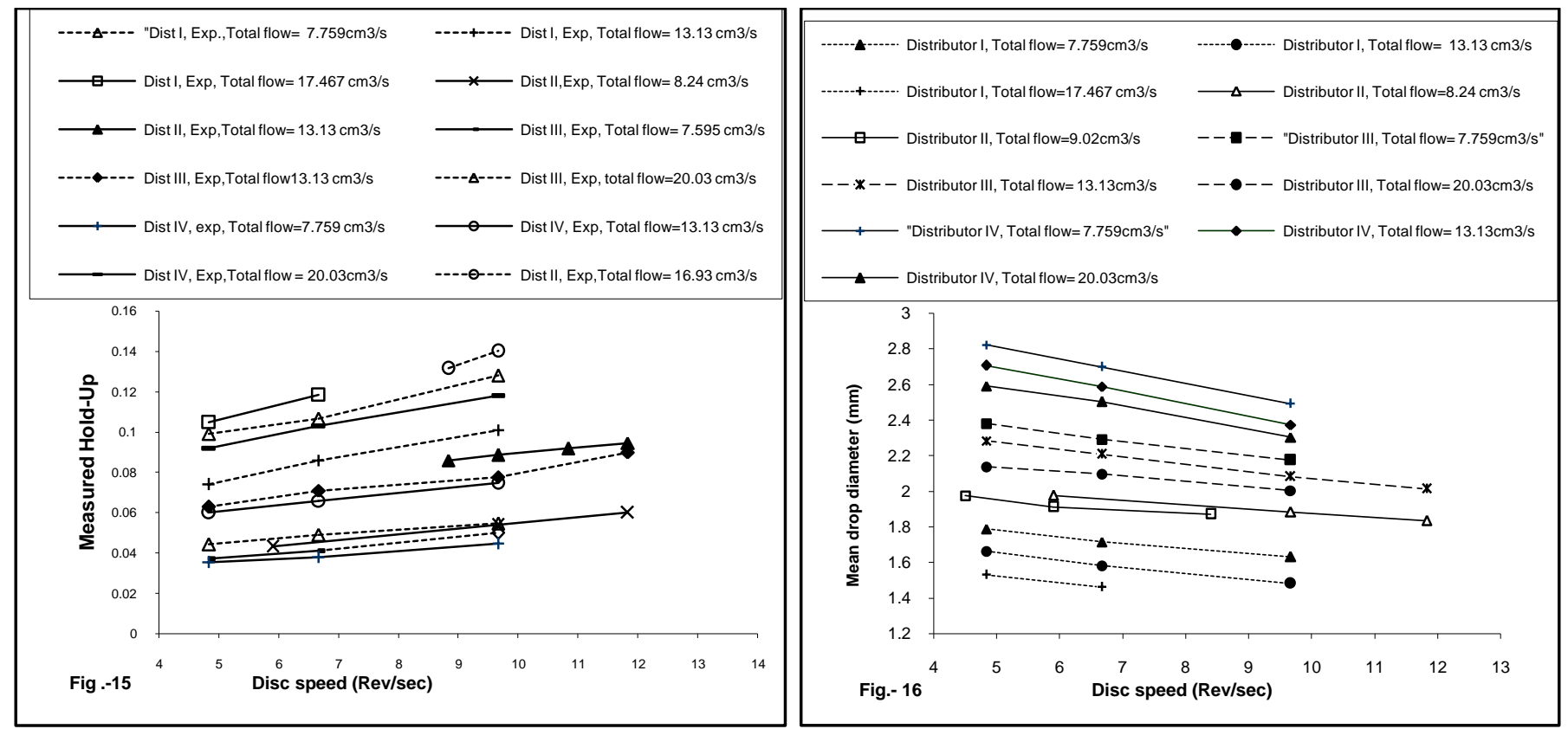

Figure -15 \& 16: Dispersed phase hold up, Effect of Disc speed (All distributors)

It is worth to mentioning that the dispersed phase holds up was more responsive to the changes in the flow rate than to the change in disc speed. This is in spite of the insignificant change in the mean drop sizes with the first and the sharp change with the latter. This may contribute mainly to two main factors; the drag forces resulted from the counter flow and from the radial and axial mixing resulted from the disc rotation.
The effect of disc speed on hold-up and drop diameter is illustrated separately for each of the four distributors as shown in Figures $(17-1,17-2,17-3,17-4) \&(18-1,18-2$, 18-3, 18-4):
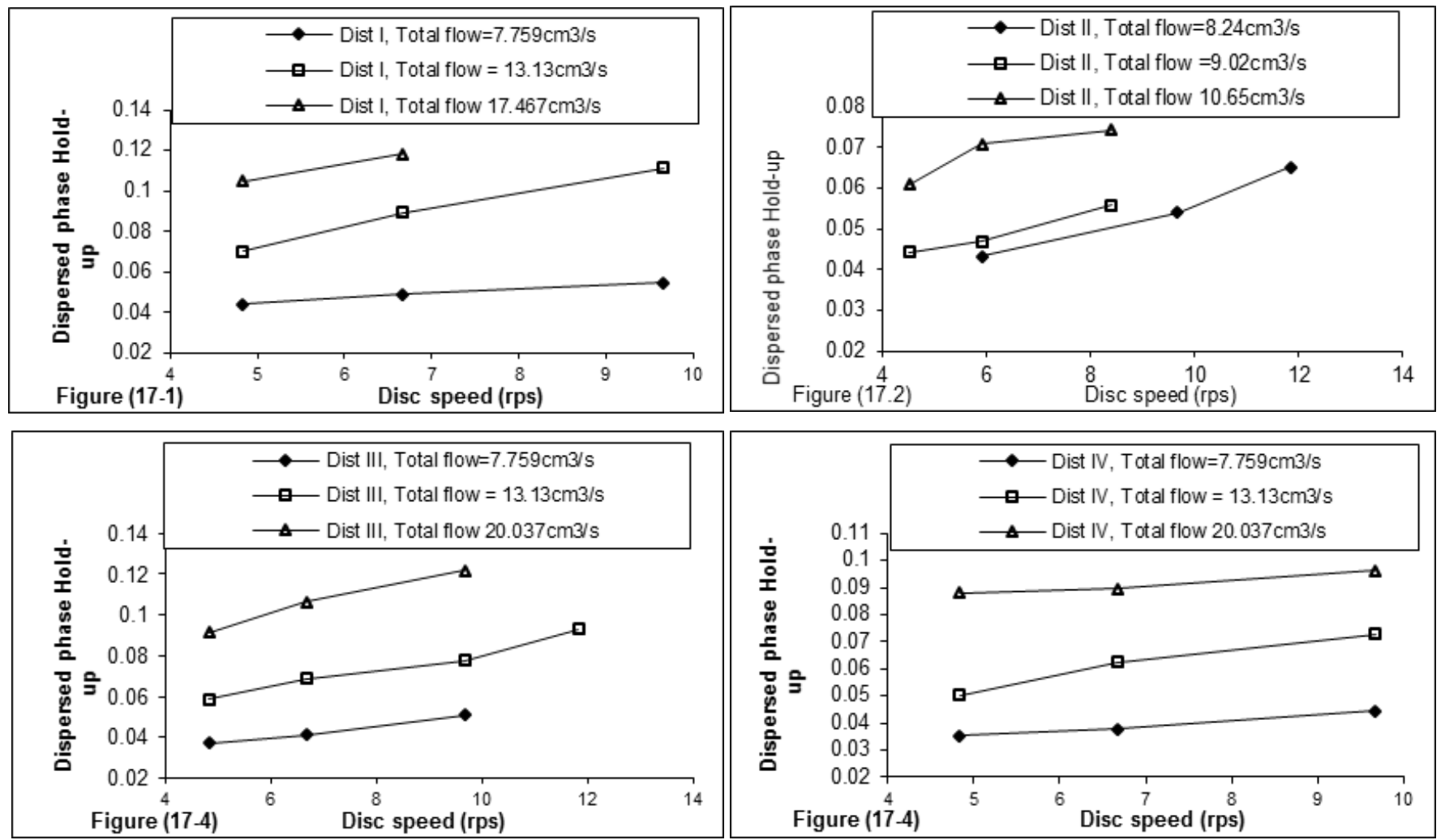

Figure-17: Dispersed phase Hold-up, effect of disc speed (Dist I, II, III, IV) 

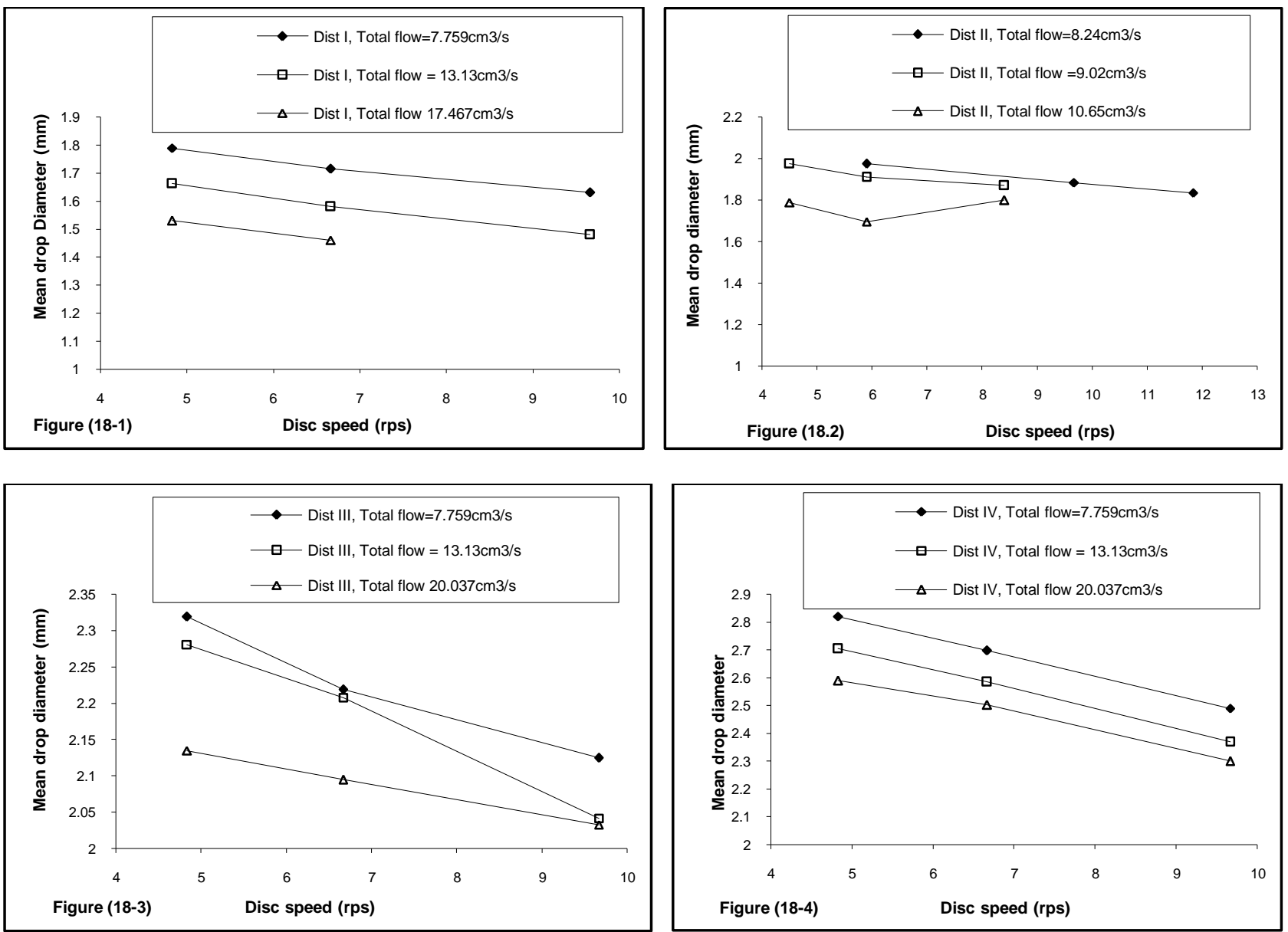

Figure- 18: Mean drop diameter, effect of disc speed (Dist I, II, III, IV)

The effect of distributor diameter on hold up, much better explained with disc speed as seen in Figure-19, the dispersed phase hold up generated in the RDC column were strongly affected by the distributor devices used. Higher dispersed hold up were obtained with smaller distributor hole diameters. This is due to smaller drop size generated from smaller hole distributors. With all runs carried out, increasing the disc speed reduced the drop diameter. For increases disc speed between 4.5 and $11.833 \mathrm{rps}$, the overall average reductions in drop diameter with distributors I, II, III, and IV were 5, 11, 26, and 42\%, respectively. The reduction would be expected to be much higher without the use of the distributors

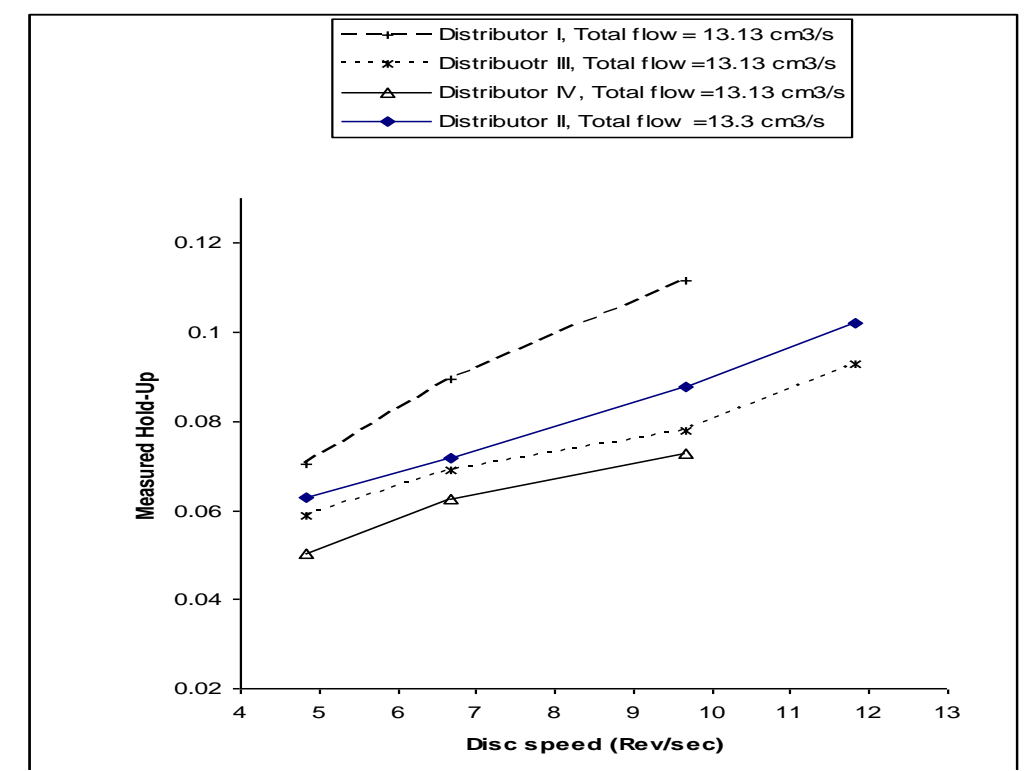

Figure- 19: Dispersed phase hold-up, effect of Distributor and disc speed 


\section{EFFECT OF SYSTEM PROPERTIES}

To checks the effect of the system properties on the dispersed phase hold up, three systems were selected. The first is (Toluene - acetone - water) system, which consider as a higher interfacial surface tension system, another two systems are; (n-butyl acetate - water) which consider intermediate interfacial surface tension system and the third with low interfacial tension system (n-Butanol - Water).
With all runs presented in the Figure-20, results were strongly affected by the system properties and distributor devices used. Higher dispersed phase hold up were observed with system have lower interfacial surface tension (nButanol - Water) than that obtain from system have high interfacial system (Toluene - Water). This is be due to larger drops generated from higher interfacial system (Toluene - Water) than that produced from lower interfacial system (n- Butanol - Water) See figure-21;
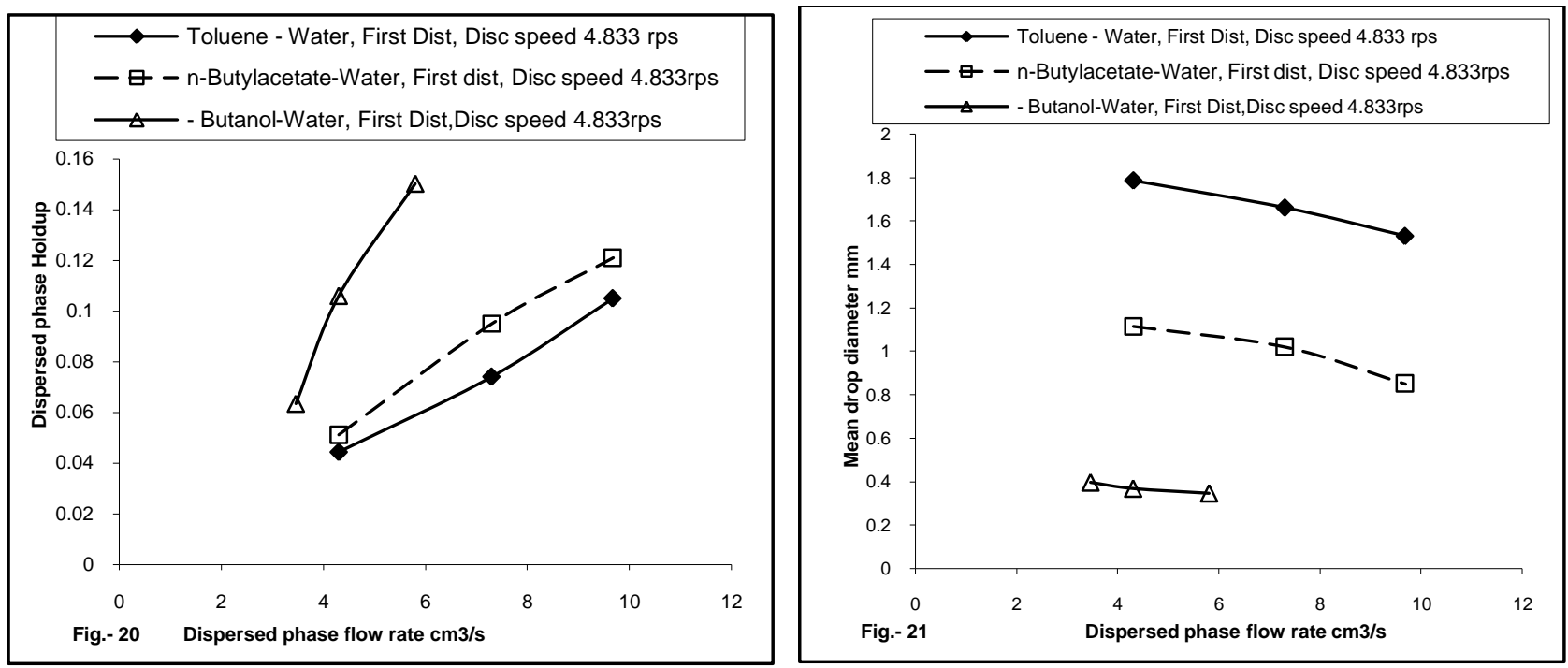

Figure-2 0 \& 21: Dispersed phase hold up experimentally measured, Effect of physical properties (Distributors I), Note: TAW, (Toluene-Acetone -Water), BW, (Butyl acetate - Water), n-BSW, (n-Butanol - Water)

Runs repeated with all distributors using the three systems, lower phase hold up were obtained with larger distributor.

The extent of variation in hold up values were not expected to always be the same for the same variation in the $\mathrm{d}_{32}$ values because the later does not represent the reality of drop size distributions inside the extractor. Nevertheless, the effect of drop size is secondary, but it is not separable from the change in the hold up.

\section{EFFECT OF SOLUTE PRESENCE AND SOLUTE CONCENTRATION}

Listed in Table- 4 are the values of the dispersed phase holdup fractions obtained from duplicate runs in which one of them was solute free and others contained solute (1.9$4.2 \%$ ww acetone). With all runs, higher dispersed phase hold-up values were obtained when solute was present.

Table-4: dispersed phase hold-up, effect of solute presence.

\begin{tabular}{|c|c|c|c|c|c|c|}
\hline & \multicolumn{2}{|c|}{ Run 1} & \multicolumn{2}{|c|}{ Run 2} & \multicolumn{2}{|r|}{ Run 3} \\
\hline Cont. phase flow rate $\left(\mathrm{cm}^{3} / \mathrm{s}\right)$ & \multicolumn{2}{|c|}{3.87} & \multicolumn{2}{|c|}{3.87} & \multicolumn{2}{|r|}{3.87} \\
\hline Disp. phase flow rate $\left(\mathrm{cm}^{3} / \mathrm{s}\right)$ & \multicolumn{2}{|c|}{3.87} & \multicolumn{2}{|c|}{6.11} & \multicolumn{2}{|r|}{6.11} \\
\hline Disc speed N (rps) & \multicolumn{2}{|c|}{11833} & \multicolumn{2}{|c|}{11.833} & \multicolumn{2}{|r|}{8.833} \\
\hline Distributor & \multicolumn{2}{|c|}{ II } & \multicolumn{2}{|c|}{ II } & \multicolumn{2}{|r|}{ II } \\
\hline Solute concentration (w.w\% ) & 1.9312 & No Solute & 1.9378 & No Solute & 2.39 & No Solute \\
\hline Mean drop diameter $(\mathrm{mm})$ & 1.648 & 1.949 & 1.620 & 1.821 & 1.805 & 2.063 \\
\hline Dispersed phase Hold-up & 0.0653 & 0.06193 & 0.0947 & 0.00878 & 0.107 & 0.0984 \\
\hline
\end{tabular}


The effect of quantity of solute concentration on dispersed phase holdup were also tested. Two sets of runs were carried out, the first contain $2.47 \%$ and the second $4.2 \%$ w.w. in water. Higher hold-up was measured with runs with higher concentration. The average difference in hold-up was $6.93 \%$. The data summarized in the Table- 5 below:

Table-5: dispersed phase hold-up, effect of quantity of solute.

\begin{tabular}{|c|c|c|c|c|}
\hline & \multicolumn{2}{|c|}{ Run 4} & \multicolumn{2}{|c|}{ Run 5} \\
\hline Dispersed phase flow rate $\mathrm{Q}_{\mathrm{c}}\left(\mathrm{cm}^{3} / \mathrm{s}\right)$ & \multicolumn{2}{|c|}{3.459} & \multicolumn{2}{|c|}{3.459} \\
\hline Continuous phase flow rate $\mathrm{Q}_{\mathrm{d}}\left(\mathrm{cm}^{3} / \mathrm{s}\right)$ & \multicolumn{2}{|c|}{4.3} & \multicolumn{2}{|c|}{4.3} \\
\hline Disc speed (rps) & \multicolumn{2}{|c|}{4.833} & \multicolumn{2}{|c|}{4.833} \\
\hline Distributor & \multicolumn{2}{|c|}{ I } & \multicolumn{2}{|c|}{ I } \\
\hline Solute concentration (w. w.\%) & 2.74 & 4.234 & 2.74 & 4.234 \\
\hline Mean drop diameter d32 (mm) & 1.785 & 1.703 & 1.381 & 1.299 \\
\hline Hold-up & 0.0443 & 0.04737 & 0.0998 & 0.1176 \\
\hline
\end{tabular}

Higher hold-up obtained with runs carried in the presence of higher solute concentration, arises from the decrease in the interfacial surface tension, which resulted in the formation of smaller drop sizes, lower residence time and as a result more dispersed phase volume.

\section{EFFECT OF COLUMN GEOMETRY}

In comparing data measured in small RDC column with data measured in large RDC column Al-Husseini [18], using same system, technique and inlet dispersed phase distributor, about same level of average mean drop diameter were obtained due to the same distributor hole diameter used in both column and the same superficial velocity used Figure-21.

Meanwhile, the dispersed phase hold-up data measured in the small column are higher than that measured in the large column, yet the drop sizes were approximately were close in sizes. This is due to the smaller compartment height of the smaller column, which contracts the dispersed phase flow and reduces drop residence time within compartment itself.
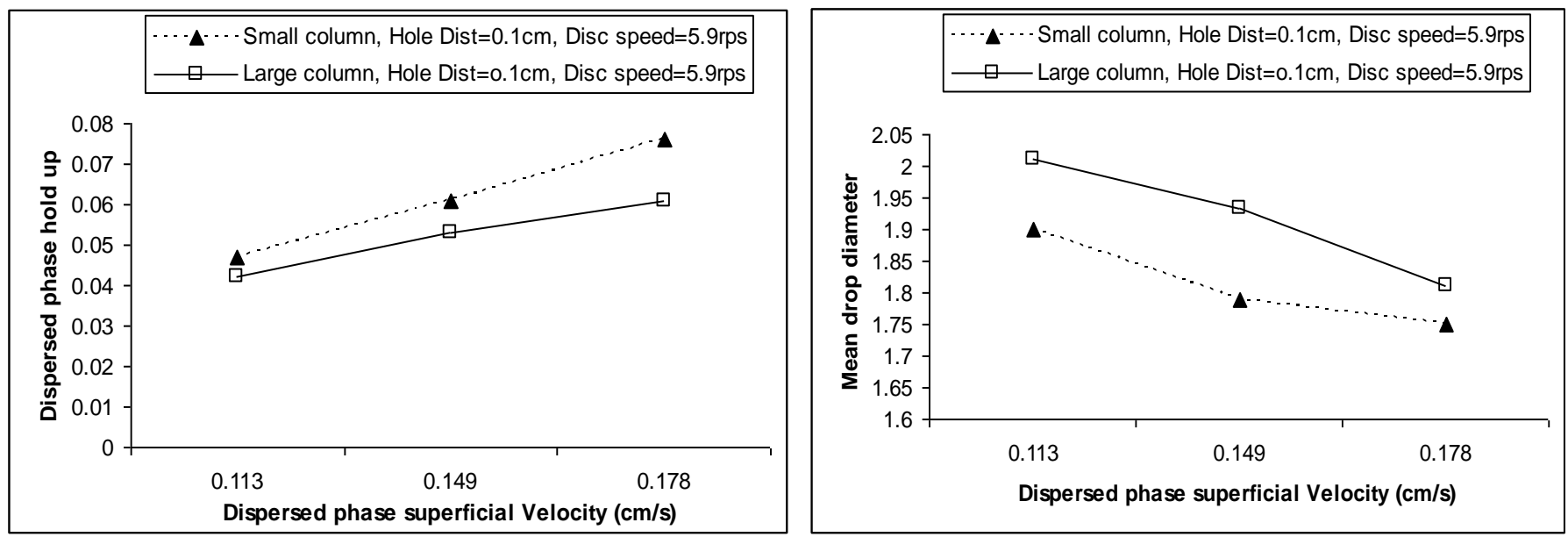

Figure- 21 \& 22: Dispersed phase hold up \& Mean drop diameter, effect of column diameter

\section{CONCLUSION:}

The effects of the dispersed phase distributor, flow rate, disc speed, physical properties, column diameter on dispersed phase hold-up and drop diameter in extractor RDC column were studied experimentally using (Toluene - Acetone Water) system, in addition to (n-butylacetate - water), and (n-Butanol - water) system over wide range of operating conditions. With first system, runs were carried out with and without mass transfer to test the influence of solute presence on hold-up.
Four different inlet holes dispersed phase distributors were use in this study. The effect of the dispersed phase inlet distributor, flow rates, disc speed and physical properties were found to be significant and dominated the dispersed phase hold-up.

It was obvious that dispersed phase hold-up increased as distributor hole diameter decreased and as disc speed, phase ratio and dispersed phase flow increased. This is mainly resulted from the direct affect and control of these variables on the drop sizes generated in the column which subsequently affect the hold-up. Meanwhile, the effect of 
the continuous phase flow rate was insignificant on drop sizes and hold-up

Physical properties of system were found dominating the dispersed phase hold-up. Lower dispersed phase hold up data were observed with system have higher interfacial surface tension (Toluene - Water) than that obtain from system have lower interfacial system (n-Butyl acetate Water and Butanol - Water).

The solute presence and concentration of solute examined; higher dispersed phase hold-up values obtained when solute was present. Meanwhile, higher hold-up obtained with runs carried in the presence of higher solute concentration, arises from the decrease in the interfacial surface tension, which resulted in the formation of smaller drop sizes, lower residence time and as a result more dispersed phase volume.

The effect of column size on dispersed phase hold-up was also tested and appeared that the dispersed phase hold-up data measured in the small column are higher than that measured in the large column. This is due to the smaller compartment height of the smaller column, which contracts the dispersed phase flow and reduces drop residence time within compartment itself.

\section{REFERENCES:}

[1] Korchinsky, W.J., and Azimzadeh-Khatalyoo, S., An improved stage-wise model of countercurrent flow liquidliquid contactors, Chem. Eng. Sci., 31, 10,871-875 (1976).

[2] Kumar, A. and Hartland, S., Independent Prediction of slip velocity and dispersed phase hold-up, in liquid-liquid extraction columns, Can. J. Chem. Eng., 67, 17-25 (1989).

[3] Godfrey J.C. and M.J. Slater, Liquid-Liquid Extraction Equipment, Wiley (1994).

[4] Cruz-Pinto,J.J.C., Korchinsky,W.J., Drop breakage in counter current flow liquid-liquid extraction columns, Chemical Engineering Science, 36, I4, 695-703, 1981.

[5] Kalaichelvi, P. and Murugesan, T., "Dispersed phase hold-up in rotary disc contactor", Bioprocess and Bio Systems Engineering, 18(2), 105-111 (1998).

[6] Stephan A. Schmidt, Martin Simon, Meanwer M. Attarakih. Luis Lagar G., Hans-Jorg

Bart. (2006) Droplet population balance modelingHydrodynamics and mass transfer. Chemical engineering Science, 61 246-256 (2006).

[7] Korchinsky, W.,J., Ismail A. M, Mass transfer parameters in rotating disc contactor, influence of column diameter, J. Chem. Tech. and Biotechnology, 43: 147-185 (1988).

[8] Jaradat' M., Menwer Attarakih and Hans-Jörg Bart' Effect of phase dispersion and mass transfer direction on steady state RDC performance using population balance modeling Chemical Engineering Journal, 165, 2, 379-387 (2010).

[9] Xiaojin, T. Guangsheng, L., and Jiading, W., "An improved dynamic combined model for evaluating the mass transfer performances in extraction column", Chemical Engineering Science., 60, 16, 4409-4421 (2005).
[10] Kirou, V. I., Tavlarides L. L., Bonnet J. C., and Tsouris C., Flooding, hold up, and drop size measurement in multistage column extractor, AIChE J., 34, 2, 283-292 (2004). columns

[11] Chartres, R. H. and Korchinsky W.J., Modelling of the liquid-liquid extraction column, Predicating the influence of drop size distribution, Trans. Inst. Chem. Eng. 53, 247 (1975).

[12] Cruz-Pinto, J.J.C., Korchinsky, W.J., Al-Husseini, R., 1983. Mass Transfer to Non-uniformDispersions in Countercurrent Flow Liquid-Liquid Extraction Columns, In Proceedings of ISEC 83, American Institute of Chemical Engineering, Denver, Conference, USA.

[13] Ribeiro M.M.M., Goncalves C, P.F. Regueiras, M.M.L. Guimaraes and Cruz Pinto J.J.C., Chem. Eng. J., 118,1-2, 47-54 (2006).

[14] Erica Moreira., L. M. Pimenta, L. L. Carneiro, R. C. L. Faria, M. B. Mansur, C. P.

Ribeiro, Hydrodynamic behavior of a rotating Disc Contactor under low agitation conditions, Chem. Eng. Comm., 192 (8), 1017-1035 (2005).

[15] Al-Rahawi, A.M.I., New Predictive Correlations for the Drop Size in a Rotating Disc Contactor Liquid-Liquid Extraction Column, Chemical Engineering \& Technology, Volume 30(2), pp. 184, 192, 2007.

[16] Onink, F., Drumm, C., Meindersma, G. W., Bart, H. J. \& de Haan, A. B. Hydrodynamic Behavior Analysis of a Rotating Disc Contactor for Aromatics Extraction with 4Methyl-Butyl-Pyridinium Center Dot BF4 by CFD. Chemical Engineering Journal, Vol. 160, No. 2, pp. 511521, (2010)

[17] R.m. sá, l.m.n.góis and c.f.cavalcanti, Dispersed phase holdup in a liquid-liquid extraction

Column, Latin American applied research 40:373-376(2010) [18] Al-Husseini, R., Estimation of Mass Transfer Model Parameters from Concentration Profile Measurements in a Liquid-liquid Extraction Column, PhD Thesis, The Victoria University of Manchester (1983).

\section{BIOGRAPHIES}

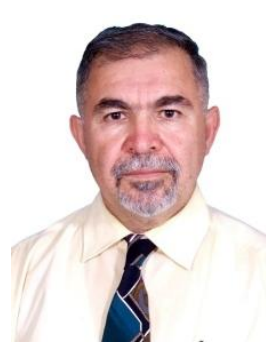

Ayham M. Al Rahawi received his Ph. D. \& M.Sc degrees in Chemical Engineering from Manchester University (UMIST) U.K, His B.Sc Chemical Engineering from Baghdad University and another B.Sc in Industrial Chemistry from Mosul University in Iraq.

He has more than 25 years' of Academic, Teaching and Research experience.

He worked as Senior Application Specialist for Stuart Energy System - Canada.

He was the founder and Head of department of chemical engineering at Nizwa University- Oman and Nasser University - Libya. 
He worked as Associate Professor for Technical University - Iraq, Seventh of April - Libya.

He was fly-ins and visiting professor to Seneca College Canada, SQ University - Oman and Suddam University Baghdad.

Currently he is working for the German University for technology (GUTech)- Oman.

He has more than 30 research publications in national, international \& Conference.

His areas of interest are Hydrodynamics and mass transfer parameters in Liquid extraction column, Separation Process, Modelling design, mathematical modeling of drop size distribution in packing column, drop size and hold up predication in RDC extraction columns. 